\title{
Plant Poisoning among Children in Rural Sri Lanka
}

\author{
M. B. Kavinda Chandimal Dayasiri, ${ }^{1}$ Shaluka F. Jayamanne, ${ }^{2}$ and Chamilka Y. Jayasinghe ${ }^{2}$ \\ ${ }^{1}$ University Paediatrics Unit, Lady Ridgeway Hospital for Children, Colombo, Sri Lanka \\ ${ }^{2}$ Faculty of Medicine, University of Kelaniya, Kelaniya, Sri Lanka
}

Correspondence should be addressed to M. B. Kavinda Chandimal Dayasiri; kavindadayasiri@gmail.com

Received 29 December 2016; Accepted 2 March 2017; Published 9 March 2017

Academic Editor: Raymond J. Hutchinson

Copyright (C) 2017 M. B. Kavinda Chandimal Dayasiri et al. This is an open access article distributed under the Creative Commons Attribution License, which permits unrestricted use, distribution, and reproduction in any medium, provided the original work is properly cited.

\begin{abstract}
Plant poisoning is a common presentation in paediatric practice and an important cause of preventable mortality and morbidity in Sri Lanka. The burden of plant poisoning is largely underexplored. The current multicenter study based in rural Sri Lanka assessed clinical profiles, poison related factors, clinical management, complications, outcomes, and risk factors associated with plant poisoning in the paediatric age group. Among 325 children, $57 \%$ were male with $64 \%$ being below five years of age. $99.4 \%$ had ingested the poison. Transfer rate was $66.4 \%$. Most had unintentional poisoning. Commonest poison plant was Jatropha circus and poisoning event happened mostly in home garden. $29 \%$ of parents practiced harmful first-aid practices. $32 \%$ of children had delayed presentations to which the commonest reason was lack of parental concern regarding urgency of seeking medical care. Presence of poisonous plants in home garden was the strongest risk factor for plant poisoning. Mortality rate was $1.2 \%$ and all cases had Oleander poisoning. The study revealed the value of community awareness regarding risk factors and awareness among healthcare workers regarding the mostly benign nature of plant poisoning in children in view of limiting incidence of plant poisoning and reducing expenditure on patient management.
\end{abstract}

\section{Introduction}

Acute poisoning in the paediatric age group is an important cause of preventable mortality and morbidity. Globally, every year 3000 children who are less than 14 years of age die following acute poisoning [1]. Children between 1 and 5 years of age have the highest risk for unintentional poisoning [2]. The type of poisons could be one of household poisons, plants, medicines, pesticides, or miscellaneous agents, and plants are identified as an important cause of paediatric poisoning reported to poison information centers [3]. Patterns of plant poisoning vary globally with varying botanical, geographical, and sociocultural characteristics among different populations [4].

Plants remain to be an important cause of mortality among adults in Sri Lanka. Two studies from Northern Sri Lanka reported Thevetia peruviana (yellow Oleander) as the commonest plant poison (17\% of cases) and it was associated with a case fatality rate of 6-7\% [5]. Similar observations were made in subsequent studies from Southern Sri Lanka [6]. Further studies on adult patients from North-Central province showed the unfavorable trend having $32-36 \%$ of patients with self-poisoning ingesting $T$. peruviana with a case fatality rate approximating 4\% [7]. Studies on plant poisoning involving Sri Lankan children however are limited. A study from Western Sri Lanka [8] identified plants as an important cause of unintentional poisoning in paediatric age group two decades ago. A prospective study (1984-2001) based on predominantly an urban population in Sri Lanka reported that plants accounted for $10 \%$ of poisoning events with a case fatality rate of $0.8 \%$ [9]. Up to date there has been no evidence from either prospective or retrospective studies with regard to plant poisoning among children from rural Sri Lanka. This multicenter study has described the patterns of plant poisoning in North-Central province of Sri Lanka (NCP) which accommodates a predominant rural community.

\section{Methods}

This multicenter prospective study included 36 hospitals in the North-Central province of Sri Lanka (Anuradhapura 
TABLE 1: Demographic characteristics, patterns of poisoning, and transfer rates of children with plant poisoning.

\begin{tabular}{|c|c|c|c|c|c|}
\hline Variable & $\begin{array}{l}\text { Retrospective study } \\
\quad(n=165)\end{array}$ & THA Study $(n=65)$ & $\begin{array}{c}\text { Polonnaruwa study } \\
(n=58)\end{array}$ & $\begin{array}{l}\text { Peripheral study } \\
\quad(n=37)\end{array}$ & $\begin{array}{c}\text { Total } \\
(n=325)\end{array}$ \\
\hline (1) Male : female & $\begin{array}{c}90: 59 \\
4.5 \%: 45.5 \%\end{array}$ & $\begin{array}{c}38: 27 \\
58.4 \%: 1.6 \%\end{array}$ & $\begin{array}{c}38: 20 \\
65.5 \%: 34.5 \%\end{array}$ & $\begin{array}{c}20: 17 \\
54 \%: 46 \%\end{array}$ & $\begin{array}{c}186: 139 \\
57 \%: 43 \%\end{array}$ \\
\hline (2) $<5$ years : $>5$ years & $\begin{array}{c}99: 66 \\
60 \%: 40 \%\end{array}$ & $\begin{array}{c}52: 13 \\
80 \%: 20 \%\end{array}$ & $\begin{array}{c}26: 32 \\
44.8 \%: 55.2 \%\end{array}$ & $\begin{array}{c}31: 6 \\
84.8 \%: 15.2 \%\end{array}$ & $\begin{array}{c}208: 117 \\
64 \%: 36 \%\end{array}$ \\
\hline (3) Unintentional : intentional & $\begin{array}{c}162: 3 \\
98 \%: 2 \%\end{array}$ & $\begin{array}{c}60: 5 \\
92 \%: 8 \%\end{array}$ & $\begin{array}{c}57: 1 \\
98.3 \%: 1.7 \%\end{array}$ & $\begin{array}{c}35: 2 \\
95.6 \%: 5.4 \%\end{array}$ & $\begin{array}{c}314: 11 \\
96.6 \%: 3.4 \%\end{array}$ \\
\hline (4) Mortality & $2(1.2 \%)$ & $1(1.5 \%)$ & $1(1.7 \%)$ & - & $4(1.2 \%)$ \\
\hline (5) Commonest poison & Jatropha circus & Jatropha circus & Jatropha circus & Jatropha circus & Jatropha circus \\
\hline (6) Transfer rate & $108(65.4 \%)$ & $49(75.3 \%)$ & $34(58.2 \%)$ & $25(67.6 \%)$ & $216(66.4 \%)$ \\
\hline
\end{tabular}

Teaching hospital (THA), Polonnaruwa District General hospital (THP), and 34 base/district/rural hospitals of the province under RDHS, Regional Director of Health Services). The study was conducted in four major arms: (1) a two-year prospective study (2012-2014) at Anuradhapura Teaching Hospital, (2) a two-year prospective study (2012-2014) at Polonnaruwa general hospital, (3) one-year prospective study involving 34 hospitals under RDHS of NCP (2013-2014), and (4) a five-year retrospective study at Anuradhapura Teaching Hospital (2007-2012). The major part of data collections was carried out at Anuradhapura hospital prospectively by the same investigator using a pretested, multistructured, interviewer administered questionnaire that comprehensively assessed clinical profiles, plant poison related factors, clinical management, complications, and outcome following acute paediatric poisoning.

Both children with intentional and unintentional poisoning were included in the assessment. Children aged 9 months to 12 years were considered for the analysis. Acute poisoning due to nonplant poisons (household poisons/medicines/pesticides), food poisons, snake envenomation, allergic reactions, and adverse drug reactions which can be considered in the purview of toxicology was omitted in the study. Also children with doubtful poisoning where there was no clear aetiology were excluded from the study. All three prospective studies identified clinical presentations, reasons for delayed management in addition to demographic data.

A prospective controlled risk factor study included all children who presented with plant poisoning to Anuradhapura Teaching Hospital over the two-year study period (20122014). The controls were selected from the same hospital and children who presented with acute medical illnesses were recruited as controls. The acute medical illnesses considered included viral fever, acute upper respiratory tract infection, and urticaria. All other acute conditions including nonspecific symptoms without a definitive diagnosis were excluded. All children were matched for age and gender on a case by case basis.

Data collections in all components of the current study were subjected to independent audit and close monitoring by South Asian Clinical Toxicology Research Collaboration (SACTRC) and the investigators of the study themselves. Ethical clearance for the study was issued by ethical review committees, faculty of medicine, University of Kelaniya, and Rajarata University of Sri Lanka.

\section{Results}

There were 325 incidents of plant poisoning reported in all arms of the study. Male children outnumbered female children in all studies and amounted to 186 (57\%). Sixtyseven percent of children were less than five years of age. However, plant poisoning was uncommon among children who were less than two years of age ( $4.6 \%$ of total) compared to older children. The majority of poisoning events were secondary to unintentional ingestion of the poison $(314 / 325$, $96.6 \%)$. Mortality rate was $1.2 \%$ (4 cases) and all four cases (100\%) followed ingestion of lethal dose of Oleander. Sixtysix percent of children (216/325) were transferred from a local hospital (under RDHS) to a tertiary care hospital following the poisoning event. Table 1 has compared the demographic characteristics, patterns of poisoning, and transfer rates of children in different arms of the study.

Jatropha curcas (Barbados nut/physic nut/poison nut) was the commonest plant poison ingested by children and it was consistently seen in all studies. Poisoning with Thevetia peruviana (Oleander) and Abrus precatorius (rosary pea/paternoster pea/wild licorice) was commonly seen after Jatropha curcas. Poisoning with those three plants comprised $83.4 \%$ of total plant poisonings. Patterns of plant poisoning were similar and consistent in all studies. Table 2 has presented all children with poisoning based on the plant ingested.

Commonest route of poisoning was ingestion (323/325, $99.4 \%)$. One child had symptoms following contact of the poison with mucus membranes. Another child indirectly ingested the poison indirectly through breast milk following her mother intentionally ingesting Oleander.

3.1. Comparison of Clinical Manifestations and Reasons for Delayed Presentations to Primary Care Hospital. 160 children recruited to studies at THA, THP, and RDHS were available for the analysis. Gastrointestinal symptoms (125 children, 78.1\%) were the predominant symptoms following plant toxin ingestion and they were consistently seen in all three 
TABLE 2: Patterns of poisoning with poisonous plants among children in North-Central province.

\begin{tabular}{|c|c|c|c|c|c|}
\hline Poisonous Plant & $\begin{array}{l}\text { Retrospective study } \\
\quad(n=165) \\
\end{array}$ & $\begin{array}{c}\text { Prospective study } \\
(n=65)\end{array}$ & $\begin{array}{l}\text { Polonnaruwa } \\
\text { study }(n=58)\end{array}$ & $\begin{array}{c}\text { Peripheral } \\
\text { study }(n=37) \\
\end{array}$ & $\begin{array}{c}\text { Total } \\
(n=325) \\
\end{array}$ \\
\hline (1) Jatropha curcas & $81(49.1 \%)$ & $22(33.8 \%)$ & $24(41.3 \%)$ & $16(43.2 \%)$ & $143(44 \%)$ \\
\hline (2) Thevetia peruviana & $36(21.8 \%)$ & $10(15.4 \%)$ & $14(24.1 \%)$ & $8(21.6 \%)$ & $68(20.9 \%)$ \\
\hline (3) Abrus precatorius & $27(16.4 \%)$ & $15(23 \%)$ & $11(19 \%)$ & $7(18.9 \%)$ & $60(18.5 \%)$ \\
\hline (4) Ricinus communis & $9(5.4 \%)$ & $5(7.7 \%)$ & $1(1.7 \%)$ & $2(5.4 \%)$ & $17(5.2 \%)$ \\
\hline (5) Jatropha multifida & $6(3.6 \%)$ & $4(6.2 \%)$ & $2(3.3 \%)$ & $-(0 \%)$ & $12(3.7 \%)$ \\
\hline (6) Caladium & $1(0.6 \%)$ & $3(4.6 \%)$ & $2(3.3 \%)$ & $2(5.4 \%)$ & $8(2.5 \%)$ \\
\hline (7) Datura stramonium & $1(0.6 \%)$ & $2(3.1 \%)$ & $1(1.7 \%)$ & $1(2.7 \%)$ & $5(1.5 \%)$ \\
\hline (8) Gloriosa superba & $1(0.6 \%)$ & $2(3.1 \%)$ & $1(1.7 \%)$ & $-(0 \%)$ & $4(1.2 \%)$ \\
\hline (9) Other & $3(1.8 \%)$ & $2(3.1 \%)$ & $2(3.3 \%)$ & $1(2.7 \%)$ & $8(2.4 \%)$ \\
\hline
\end{tabular}

TABLE 3: Clinical manifestations of plant poisoning among children in rural Sri Lanka.

\begin{tabular}{lcccc}
\hline Reasons for delayed presentation & THA & THP & RDHS & Total \\
\hline (1) Gastrointestinal symptoms & $59(90.1 \%)$ & $41(70.6 \%)$ & $25(67.5 \%)$ & $125(78.1 \%)$ \\
(2) Respiratory symptoms & $25(38.4 \%)$ & $22(37.9 \%)$ & $16(43.2 \%)$ & $63(39.3 \%)$ \\
(3) Cardiovascular symptoms & $3(4.6 \%)$ & $6(10.3 \%)$ & $2(6.4 \%)$ & $11(6.8 \%)$ \\
(4) Neurological symptoms & $2(3 \%)$ & $1(1.7 \%)$ & - & $3(1.8 \%)$ \\
\hline
\end{tabular}

studies. Most gastrointestinal symptoms occurred following Jatropha circus intoxication. All children with cardiovascular symptoms were intoxicated with Oleander. Table 3 illustrates the variability in clinical manifestations in detail.

Fifty-two children (32.5\%) presented to primary care hospital at least two hours after the ingestion of the poison. Commonest reason for delayed presentation was lack of concern regarding urgency of the situation, 33 children (20.6\%). Detailed analysis of reasons for delayed presentation to primary care unit is presented in Table 4.

3.2. Detailed Evaluation of Patterns and Risk Factors of Plant Poisoning among Children at THA. Sixty-five children presented to THA following plant poisoning over the twoyear study period. Mean age of children was 4.3 years (range: 11 months-12 years). Most parents had received secondary education, 50 fathers (77\%) and 54 mothers (83.1\%). The majority of fathers were engaged in farming $(21,32.3 \%)$, defense service $(11,16.9 \%)$, and manual labour (11, 16.9\%). Most mothers were housewives $(45,69.2 \%)$. Most of the poisoning events occurred in home garden $(43,66.1 \%)$ followed by cultivation area $(12,18.4 \%)$ and inside of home $(5,7.7 \%)$.

Harmful first-aid measures were practiced in 19 children (29.2\%). The commonest measure was forceful ingestion of water $(8,12.3 \%)$ and it was followed by forceful finger insertion $(3,4.6 \%)$, forceful milk $(2,3.1 \%)$, and coconut milk ingestion $(2,3.1 \%)$.

The majority of children had onset of symptoms within one hour from the time of poisoning event (35, 53.8\%). Though most children $(45,69.2 \%)$ were brought to primary care unit within two hours from the poisoning event, twenty children $(31.8 \%)$ presented at least 2 hours after the poison was ingested (range: 2 to 8 hours). Emesis induction was offered to 32 children (49.2\%). Two children $(3.1 \%)$ required prescription of antidotes and management in an intensive care unit. Reported medical complications included cardiac arrhythmia (2) (3.1\%), severe dehydration (1) (1.5\%), hematemesis (1) (1.5\%), and seizures (1) (1.5\%).

Risk factor evaluation showed four proposed risk factors which were associated with significantly elevated risk $(p<$ 0.001 ) of plant poisoning among children. They were the presence of poisoning pants in home garden, inadequate supervision of the child, past history of poisoning, and parents' subjective feeling of lack of family support to look after children. Five proposed risk factors did not reveal a significant association with plant poisoning (working mother, children with deprived schooling, young mother, poorly educated mother, farming parents, and parents' subjective perception of having economic problems). Table 5 has compared the presence of proposed risk factors in the two groups.

\section{Discussion}

Plant poisoning in children is one of the common presentations to emergency departments. However, the risk factors and circumstances of these poisoning events are largely underexplored in international literature [10] and most studies have concentrated on data reported to poison information centers. The pattern of plant poisoning varies considerably based on age, sex, and sociodemographic factors among different geographic regions [11]. Young children comprise a unique group in that they have the natural curiosity about their surroundings and tendency for oral exploration keeping them highly vulnerable to unintentional poisoning [12].

The current study identified male children more vulnerable than female children for plant poisoning. Furthermore, it also revealed that the majority of children were between 2 and 
TABLE 4: Reasons for delayed presentation to primary care unit among children in rural Sri Lanka.

\begin{tabular}{|c|c|c|c|c|}
\hline Reasons for delayed presentation & THA & THP & RDHS & Total \\
\hline (1) Lack of concern regarding need for urgent care & $12(18.4 \%)$ & $11(18.9 \%)$ & $10(27 \%)$ & $33(20.6 \%)$ \\
\hline (2) Lack of transport facilities for emergency management & $8(12.3 \%)$ & $7(12 \%)$ & $12(32.4 \%)$ & $25(15.6 \%)$ \\
\hline (3) Lack of knowledge regarding possible complications & $6(9.2 \%)$ & $6(10.3 \%)$ & $4(10.8 \%)$ & $16(10 \%)$ \\
\hline (4) Lack of financial resources & $6(9.2 \%)$ & $4(6.8 \%)$ & $2(5.4 \%)$ & $12(7.5 \%)$ \\
\hline (5) Poisoning event unrevealed until symptoms occurred & $2(3.1 \%)$ & $1(1.7 \%)$ & $1(2.7 \%)$ & $4(2.5 \%)$ \\
\hline (6) Delayed attention by medical team & $1(1.5 \%)$ & - & - & $1(0.6 \%)$ \\
\hline
\end{tabular}

TABLE 5: Analysis of proposed risk factors in case-control study.

\begin{tabular}{|c|c|c|c|c|}
\hline Proposed risk factor & Cases & Controls & Chi square value & $p$ value \\
\hline (1) Poisonous plants in home garden & 54 & 6 & 71.31 & $<0.001$ \\
\hline (2) Inadequate supervision of the child & 49 & 13 & 39.96 & $<0.001$ \\
\hline (3) Past history of poisoning & 24 & 2 & 23.26 & $<0.001$ \\
\hline (4) Lack of family support & 33 & 12 & 14.98 & $<0.001$ \\
\hline (5) Mother working during the daytime & 17 & 15 & 0.16 & 0.68 \\
\hline (6) Lack of schooling/education in mother & 2 & 1 & 0.34 & 0.55 \\
\hline (7) Young mother ( $<19$ years) & 7 & 9 & 0.28 & 0.59 \\
\hline (8) Primary level education in mother & 10 & 7 & 0.60 & 0.43 \\
\hline (9) Parents from farming community & 22 & 19 & 0.32 & 0.57 \\
\hline (10) Economic problems & 21 & 20 & 0.03 & 0.85 \\
\hline
\end{tabular}

5 years of age. Unintentional poisoning accounted for more than $90 \%$ of poisoning events and almost all cases had taken the poison through ingestion. Similar observations are made in previously published studies from Sri Lanka [9], India [10], Thailand [13], and Taiwan [14].

A key observation in the current study was the higher transfer rate of children. The study identified that $66.4 \%$ of total population were transferred between two hospitals and $67.2 \%$ of children who attended local hospitals under RDHS were subsequently transferred to a tertiary hospital for further management. Previously published adult studies in the same region of Sri Lanka observed a transfer rate of $50 \%$ [15] which is lower than current figures. Despite higher transfer rates, case fatality and complication rates in current study were significantly lower than adult studies [7]. Transferring of patients significantly adds to healthcare expenditure and the average patient cost per transfer was US\$ 14.03 in one study eight years before in the same region [16]. These facts reveal the value of increased awareness among healthcare workers in rural territories regarding the nature and outcome of plant poisoning in the paediatric age group which is mostly benign. Effective triage and limitation of transfers only to needy children would likely cut down healthcare expenditure, duration of hospital stay, and effect on families of children with plant poisoning.

We observed a higher percentage of deliberate ingestions compared to a previously published study in urban Sri Lanka [9]. In that study, the common plant poisons were Jatropha circus, Ricinus communis, and Jatropha multifida (physic nut/nettle spurge) accounting for $43 \%$ of total plant poisonings. In the current study based on NCP, Jatropha circus, Oleander, and Abrus precatorius were identified in
$83.4 \%$ of all plant poisonings. All deliberate poisonings happened by ingestion of Oleander. These poisonous plants were usually found in fences of houses, by sides of walking paths and canals. Some were in fact grown as house plants by parents. Higher proportion of deliberate poisoning with Oleander raises the question as to how they learn these behaviours given the fact that NCP has higher numbers of suicides among adults [1].

It was also revealed that $78.5 \%$ of children had ingested plant poisons within their own home gardens or neighborhoods. This figure of $78.5 \%$ is much higher compared to previous Sri Lankan studies conducted in more urban areas [9] and underpins hazardous nature of home gardens and neighborhoods of remote villages which accommodate poisonous plants without being noticed by house owners. Higher rates of transfers from many rural territories within the province compared to other poison types [17] also highlight widespread distribution of environmental risk factors within the community.

Home garden was the commonest place for poisoning with plant seeds in current study. A study from urban Sri Lanka observed Alocasia (elephant's ear plant) as the commonly encountered plant poison in home garden [18]. In our study, commonly encountered plant poisons in home gardens were Jatropha circus, Abrus precatorius, and Oleander. Home gardens in remote areas of NCP are less cleared allowing growth of these plants and most parents were unaware of the potential toxicity. Jatropha circus was identified as the commonest poison in current study and Jatropha circus induced gastrointestinal symptoms were the commonest clinical presentation. The same observation has been made in studies from other parts of Sri Lanka [9] and Asia [13]. 
Patterns of poisoning and as well as subsequent outcome are always related to the underlying sociocultural circumstances. Observation of scientifically unproven yet culturally based first-aid practices by some parents as observed in this study can be associated with detrimental effects. Therefore providing knowledge to at-risk communities regarding such issues is helpful in bringing down childhood poisoning related morbidity and mortality.

Delayed presentation to primary care hospital following the poisoning event has a potentially strong negative impact on effective management and patient outcomes [19]. In the current study, the commonest reason for delayed presentation had been lack of concern regarding the urgency for seeking medical care. Child remaining asymptomatic after ingestion, lack of identity of the ingested substance as a poison, and small ingested amount of poison had kept a higher threshold for some parents to seek urgent medical attention. The duration of hospital stay and severity of complications have been shown to have a direct correlation with lag time in reaching the hospital following the poisoning event [20]. These facts reveal the value of community awareness in seeking early primary care in improving patient outcomes.

The current study identified four factors including presence of poisoning plants in home garden, inadequate supervision, past history of poisoning, and parents' subjective feeling of lack of family support to look after children as being associated specifically with significantly elevated risk of plant poisoning in children. Schmertmann et al. reported inadequate supervision as a risk factor for unintentional poisoning in the paediatric age group [21]. Similarly, past history of poisoning has been identified as a risk factor for acute poisoning [22]. However, evidence regarding risk factors for plant poisoning by properly controlled studies is scant in currently available literature and further studies are needed. As majority of plant poisoning occurred within home premises in the current study, a holistic approach which targets home environment would help in managing the burden of poisoning.

\section{Conclusion}

The study revealed harmful effects of traditional first-aid practices which are detrimental to health of the child. Children become victims of plant poisoning mostly secondary to presence of poisoning plants in home garden, inadequate supervision by care givers, and previous poisoning. As these risk factors are significantly associated with plant poisoning, the effect of community education to enhance vigilance and assurance of safe environment should be evaluated. The study also identified the importance of awareness among healthcare workers regarding the mostly benign nature of plant poisoning in children in view of reducing expenditure on patient management.

\section{Ethical Approval}

The study was granted ethical approval by ethical review committees of Faculties of Medicine, University of Kelaniya, and Rajarata University of Sri Lanka.

\section{Consent}

Parents of all participants gave written consent for participation of their children in the study and publication of results.

\section{Conflicts of Interest}

The authors declare that they have no conflicts of interest.

\section{Authors' Contributions}

M. B. Kavinda Chandimal Dayasiri designed the study, carried out data collection following appropriate methodology, analysed data, and wrote the manuscript. Shaluka F. Jayamanne and Chamilka Y. Jayasinghe designed the study, analysed data, and supervised manuscript writing process.

\section{Disclosure}

No external funding was obtained for this study.

\section{Acknowledgments}

The authors of this study acknowledge Dr. Suneth Agampodi, Head of Department of Community Medicine, and Dr. Lalith Senarathna, Senior Lecturer, Faculty of Applied Sciences, Rajarata University of Sri Lanka, for providing technical advice in data analysis, and Dr. Thilini Hemachandra and Dr. Chamila Dissanayaka of Anuradhapura Teaching Hospital, Sri Lanka, for providing support in entering data into statistical databases.

\section{References}

[1] "The global burden of disease: 2004 update," World Health Organization, Geneva, Switzerland, 2008, http://www.who.int/ healthinfo/global_burden_disease/GBD_report_2004update_ full.pdf.

[2] World Health Organization, World Health Organization Mortality Database, World Health Organization, Geneva, Switzerland, 2003, http://www.who.int/whosis.

[3] E. P. Krenzelok and R. Mrvos, "Friends and foes in the plant world: a profile of plant ingestions and fatalities," Clinical Toxicology, vol. 49, no. 3, pp. 142-149, 2011.

[4] J. Pronczuk de Garbino and A. Laborde, "Plants that poison in Uruguay," Journal of Toxicology: Clinical Toxicology, vol. 22, no. 1, pp. 95-102, 1984.

[5] T. Ganesvaran and R. Rajarajeswaran, "Fatal deliberate selfharm seen in a Sri Lankan hospital," British Journal of Psychiatry, vol. 152, pp. 420-423, 1988.

[6] J. Hettiarachchi and G. C. S. Kodithuwakku, "Pattern of poisoning in rural sri lanka," International Journal of Epidemiology, vol. 18, no. 2, pp. 418-422, 1989.

[7] M. Eddleston, M. H. R. Sheriff, and K. Hawton, "Deliberate self harm in Sri Lanka: an overlooked tragedy in the developing world," British Medical Journal, vol. 317, no. 7151, pp. 133-135, 1998.

[8] R. Fernando and D. N. Fernando, "Childhood poisoning in Sri Lanka," Indian Journal of Pediatrics, vol. 64, no. 4, pp. 457-460, 1997. 
[9] G. N. Lucas, "Plant poisoning in Sri Lankan children: a hospital based prospective study," Sri Lanka Journal of Child Health, vol. 35, no. 4, pp. 111-124, 2008.

[10] D. J. Sharma, "Profile of poisoning in children," Pediatric Oncall, vol. 11, no. 2, 2014.

[11] R. Khadgawat, P. Garg, P. Bansal, A. Arya, and B. Choudhary, "Accidental poisoning," Indian Pediatrics, vol. 31, no. 12, pp. 1555-1557, 1994.

[12] T. J. Meredith, "Epidemiology of poisoning," Pharmacology and Therapeutics, vol. 59, no. 3, pp. 251-256, 1993.

[13] C. Sriapha, A. Tongpoo, S. Wongvisavakorn et al., "Plant poisoning in Thailand: a ten year analysis from Ramathibodi poison center," The Southeast Asian Journal of Tropical Medicine and Public Health, vol. 46, no. 6, pp. 1063-1076, 2015.

[14] C. C. Yang, J.-F. Wu, H.-C. Ong, Y.-P. Kuo, J.-F. Deng, and J. Ger, "Children poisoning in Taiwan," Indian Journal of Pediatrics, vol. 64, no. 4, pp. 469-483, 1997.

[15] M. Eddleston, K. Sudarshan, M. Senthilkumaran et al., "Patterns of hospital transfer for self-poisoned patients in rural Sri Lanka: implications for estimating the incidence of self-poisoning in the developing world," Bulletin of the World Health Organization, vol. 84, no. 4, pp. 276-282, 2006.

[16] K. Wickramasinghe, P. Steele, A. Dawson et al., "Cost to government health-care services of treating acute self-poisonings in a rural district in Sri Lanka," Bulletin of the World Health Organization, vol. 87, no. 3, pp. 180-185, 2009.

[17] M. B. K. C. Dayasiri, S. F. Jayamanne, and Y. C. Jayasinghe, "Patterns and risk factors of childhood poisoning in rural Sri Lanka," in Proceedings of the 15th Annual Meeting of the Asia Pacific Medical Tpxicology Association, Novena, Singapore, November 2016.

[18] G. N. Lucas, "Plant poisoning : a hospital-based study in Sri Lanka," Indian Journal of Pediatrics, vol. 64, no. 4, pp. 495-502, 1997.

[19] S. Babu, D. G. Chandrika, and M. R. Kulkarni, "Plant poisoning-an observational study in a tristate region emergency department," International Journal of Medical Science and Public Health, vol. 5, no. 10, pp. 2158-2161, 2016.

[20] N. Mittal, N. Shafiq, A. Bhalla, P. Pandhi, and S. Malhotra, "A prospective observational study on different poisoning cases and their outcomes in a tertiary care hospital," SAGE Open Medicine, vol. 1, 2013.

[21] M. Schmertmann, A. Williamson, D. Black, and L. Wilson, "Risk factors for unintentional poisoning in children aged 1-3 years in NSW Australia: A Case-Control Study," BMC Pediatrics, vol. 13, no. 1, article 88, 2013.

[22] T. L. Litovitz, S. L. Flagler, A. S. Manoguerra, J. C. Veltri, and L. Wright, "Recurrent poisonings among paediatric poisoning victims," Medical Toxicology and Adverse Drug Experience, vol. 4, no. 5, pp. 381-386, 1989. 


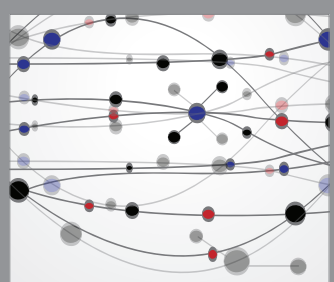

The Scientific World Journal
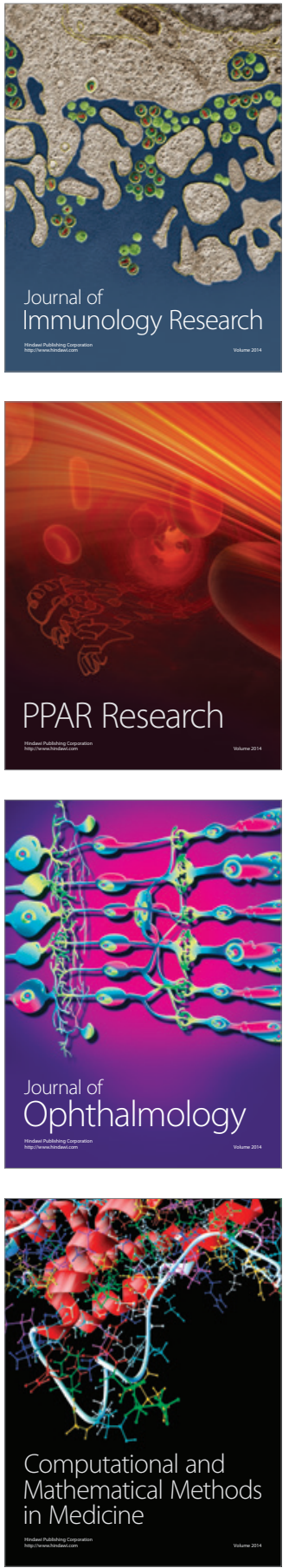

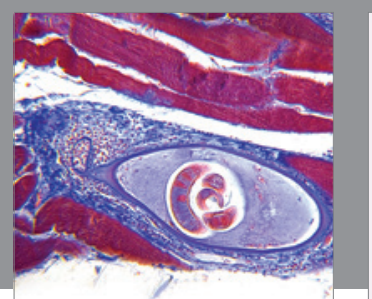

Gastroenterology Research and Practice
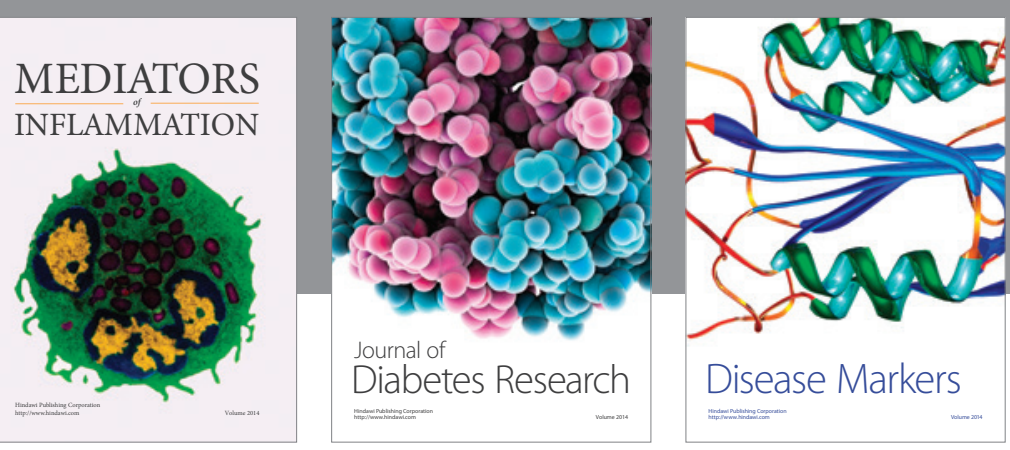

Disease Markers

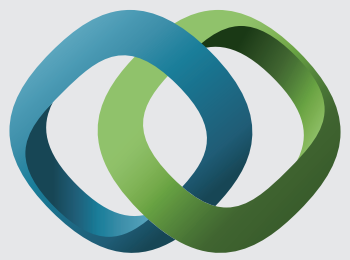

\section{Hindawi}

Submit your manuscripts at

https://www.hindawi.com
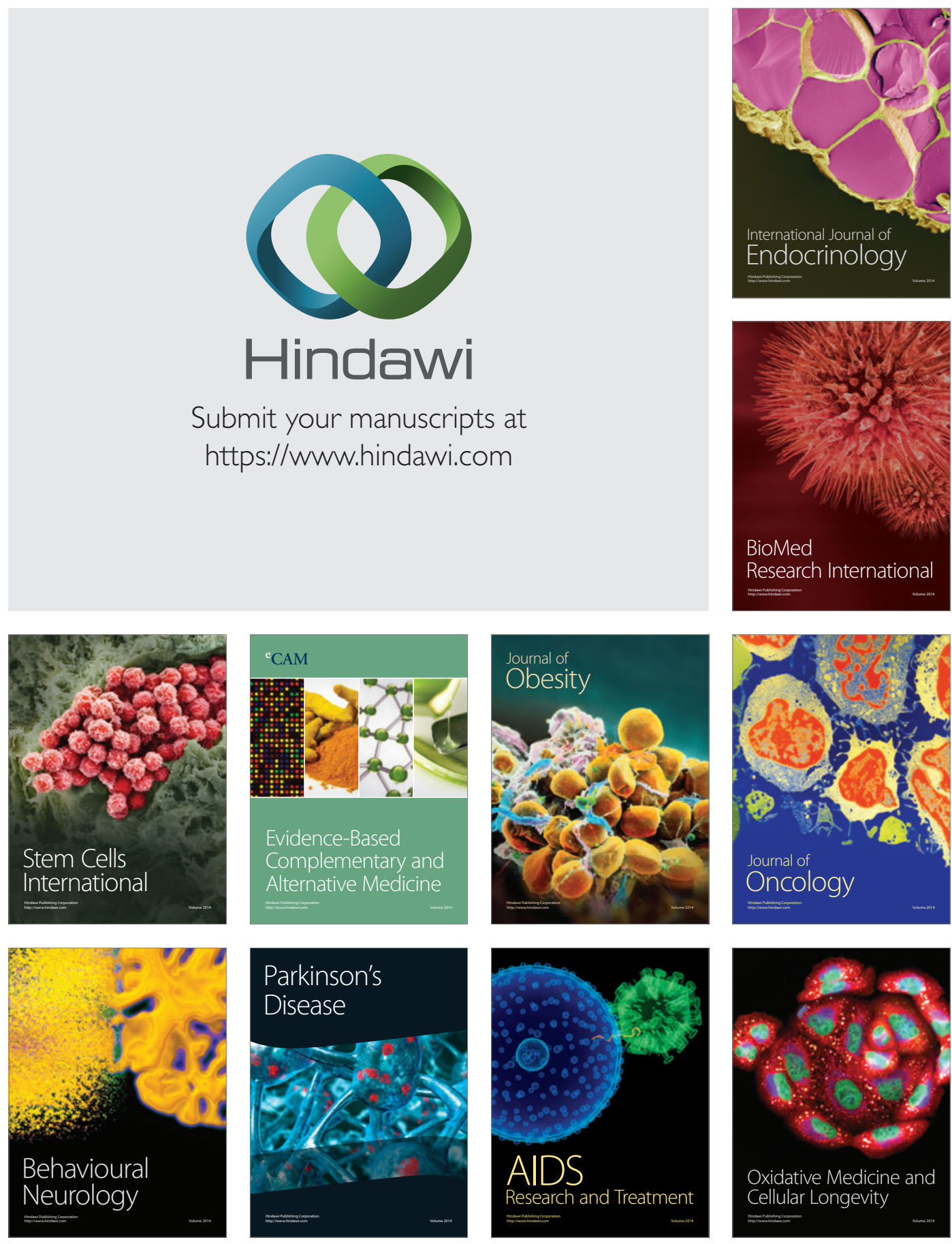